\title{
UNDIFFERENTIATED CONNECTIVE TISSUE DISEASE ASSOCIATED WITH METASTATIC SEMINOMA: A RARE CASE REPORT
}

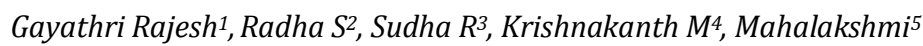

${ }^{1}$ Senior Resident, Department of Dermatology, Sri Ramachandra University. 2Junior Resident, Department of Dermatology, Sri Ramachandra University. ${ }^{3}$ Professor, Department of Dermatology, Sri Ramachandra University.

${ }^{4}$ Associate Professor, Department of Dermatology, Sri Ramachandra University.

5 Professor, Department of Dermatology, Sri Ramachandra University.

\begin{abstract}
Many autoimmune diseases have been reported to be associated with malignancies with an incidence rate of 5\%.(1) A 30-year male with recurrent edema of the lips and periorbital area with itching and pain for 6 weeks. He had both extremity weakness with upper back pain for 1 month. H/O loss of weight and appetite for 1 yr. With this clinical picture, a diagnosis of angioedema/dermatomyositis (CTD) was suspected. CPK and CPK-MB within normal limits, antinuclear antibodies + by IF with titre of 1:320 with nucleus-granular pattern suggesting autoantibodies against U1-RNP Antigen/Sm Antigen. USG scrotum- a single testes. MRI-spine revealed multiple peripancreatic, pre- and para-aortic and left supraclavicular lymph nodes with nodules in both lungs. CT Thorax and CT Abdomen showed liver and lung metastasis with periportal and vertebral lymph nodes. FNAC left supraclavicular node-positive for malignant cells, suggestive of metastatic malignant germ cell tumor. Tumor markers-elevated (aFP-180, bHCG457.2.
\end{abstract}

\section{KEYWORDS}

Recurrent Episodes, Edema, Limb Weakness, Scrotal Surgery, ANA + ve.

HOW TO CITE THIS ARTICLE: Rajesh G, Radha S, Sudha R, et al. Undifferentiated connective tissue disease associated with metastatic seminoma: A rare case report. J. Evolution Med. Dent. Sci. 2016;5(7):346-347, DOI: 10.14260/jemds/2016/76

\section{INTRODUCTION}

Many autoimmune diseases have been reported to be associated with malignancies with an incidence rate of $5 \%$. However, the association is rare in Undifferentiated Connective Tissue Disease (UCTD). We report a case of UCTD in association with metastatic seminoma.

\section{CASE REPORT- HISTORY}

A 30-year male was admitted with recurrent episodes of edema of the lips and periorbital area associated with itching and pain, on and off for 6 weeks. He had both extremity weakness with upper back pain not relieved with antispasmodics for 1 month. He gave h/o an operative procedure done in his scrotal area (details not available). $\mathrm{H} / \mathrm{O}$ loss of weight and appetite for 1 year. With this clinical picture a diagnosis of angioedema/dermatomyositis (CTD) was suspected.

0/E -he was emaciated and pale. There was proximal muscle weakness (Neck, shoulders, hip).

\section{LABORATORY DATA}

Normocytic anemia, CPK and CPK-MB within normal limits, antinuclear antibodies + by IF with titre of $1: 320$ with nucleusgranular pattern suggesting autoantibodies against U1-RNP Antigen/Sm Antigen.

Financial or Other, Competing Interest: None.

Submission17-11-2015, Peer Review 21-11-2015,

Acceptance 27-11-2015, Published 25-01-2016.

Corresponding Author:

Dr. Gayathri Rajesh,

Plt. No. 212, $8^{\text {th }}$ Sector,

$42^{\text {nd }}$ Street, K. K. Nagar,

Chennai.

E-mail:groovygaya@hotmail.com

DOI: 10.14260/jemds/2015/76
USG scrotum- a single testes. In view of persistent muscle weakness and back pain MRI-spine was done-revealed multiple peripancreatic, pre- and para-aortic and left supraclavicular lymph nodes with nodules in both lungs. CTThorax-lung metastasis with mediastinal, paratracheal and left supraclavicular lymph nodes. CT-whole abdomen-liver and lung metastasis with periportal and vertebral lymph nodes. FNAC left supraclavicular node-positive for malignant cells, suggestive of metastatic malignant germ cell tumor. Tumor markers- elevated (aFP-180, bHCG-457.2).

\section{CONCLUSION}

Seminoma carries a good prognosis when treated with metastasis; however, its association with UCTD might alter the prognosis. Cases of malignant thymoma, gastric and uterine cervix carcinomas in association with UCTD have been reported earlier; hence, this case is probably the first of its kind to be associated with seminoma and is presented for its rarity.

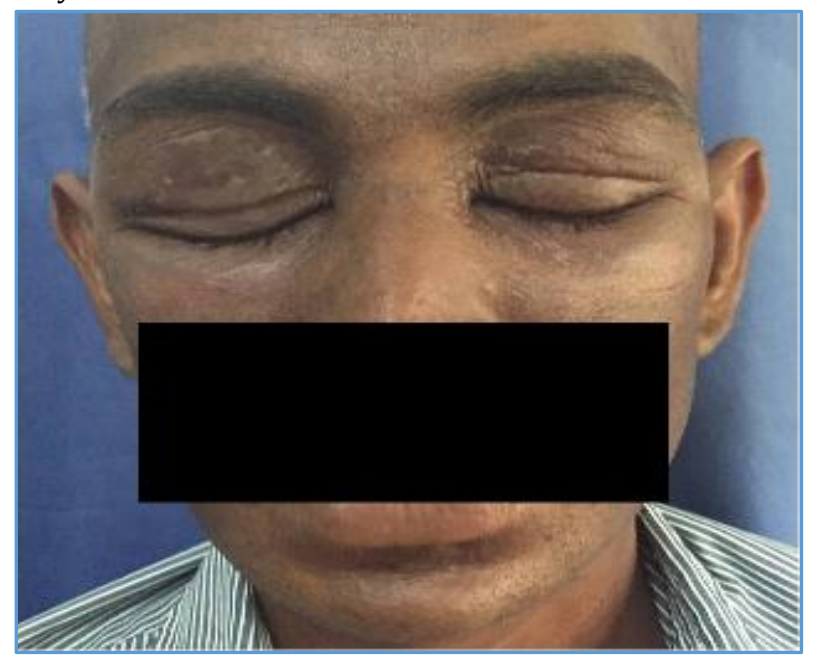

Fig. 1: The Patient with Facial Swelling 


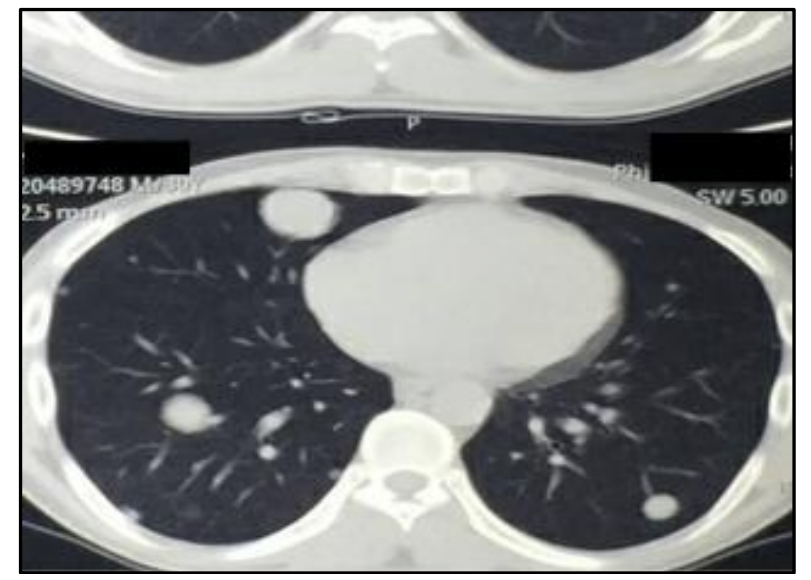

Fig. 2: Lung with Metastasis

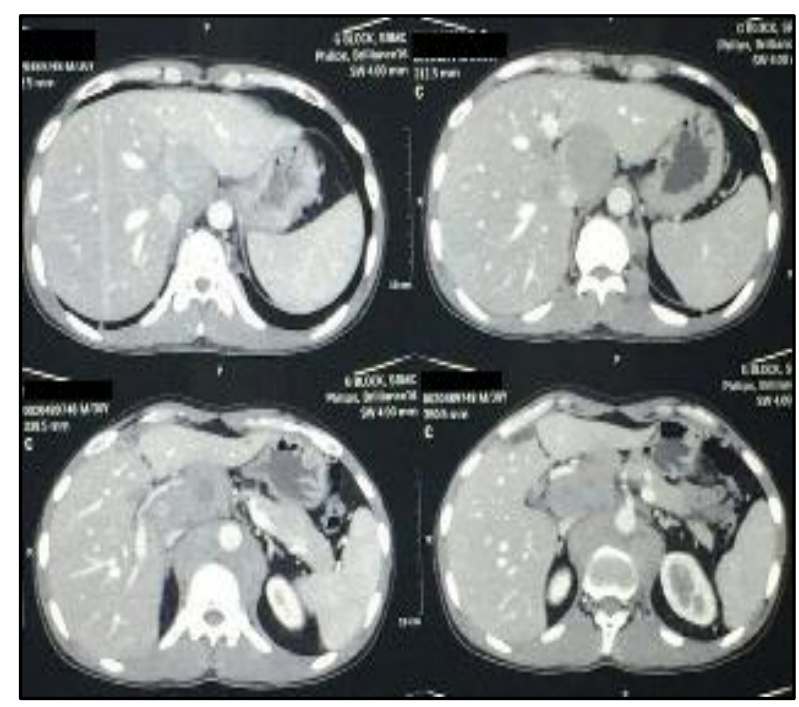

Fig. 3: Lung and Liver with Metastasis

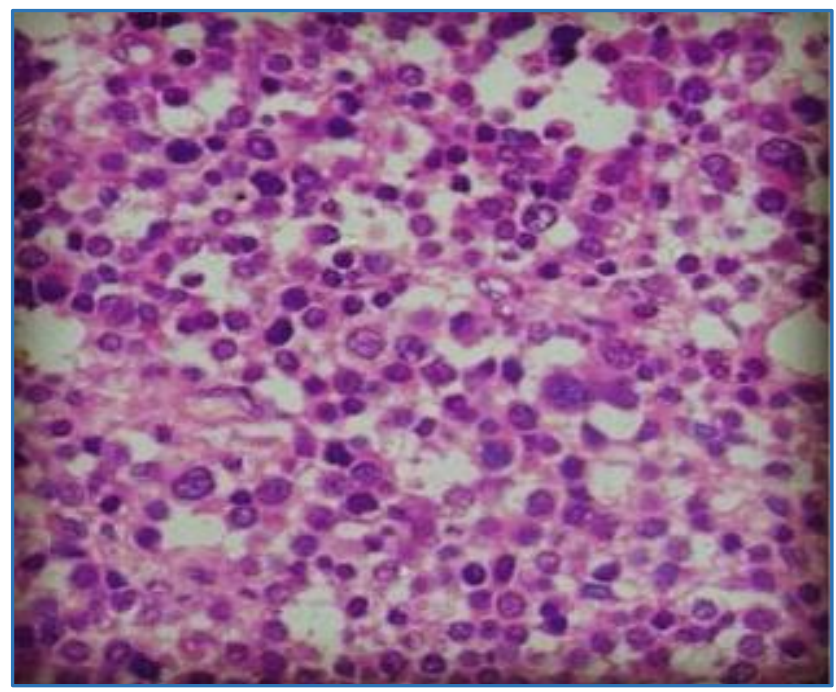

Fig. 4: FNAC with Malignant Cells

\section{REFERENCES}

1. Patricia Tai. University of Saskatchewan Edward Yu, The University of Western Ontario, edward.yu@lhsc.on.ca. Kurian Joseph, University of Alberta. Thomas Miale, Allan Blair Cancer Clinic. A Review of Autoimmune Diseases Associated with Cancer, SK1-1-2010. 